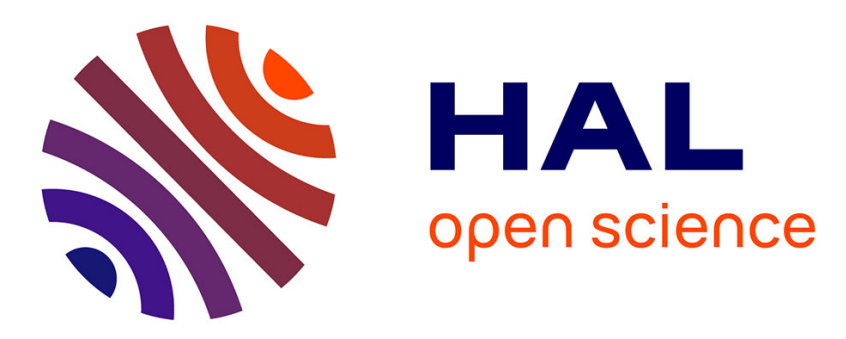

\title{
Interband contribution to transition radiation from metals
}

\author{
H. Dallaporta, A. Humbert, J.M. Debever, J. Hanus
}

\section{To cite this version:}

H. Dallaporta, A. Humbert, J.M. Debever, J. Hanus. Interband contribution to transition radiation from metals. Journal de Physique Lettres, 1982, 43 (21), pp.733-737. 10.1051/jphyslet:019820043021073300 . jpa-00232118

\section{HAL Id: jpa-00232118 https://hal.science/jpa-00232118}

Submitted on 1 Jan 1982

HAL is a multi-disciplinary open access archive for the deposit and dissemination of scientific research documents, whether they are published or not. The documents may come from teaching and research institutions in France or abroad, or from public or private research centers.
L'archive ouverte pluridisciplinaire HAL, est destinée au dépôt et à la diffusion de documents scientifiques de niveau recherche, publiés ou non, émanant des établissements d'enseignement et de recherche français ou étrangers, des laboratoires publics ou privés. 
Classification

Physics Abstracts

78.90

\title{
Interband contribution to transition radiation from metals
}

\author{
H. Dallaporta, A. Humbert, J. M. Debever and J. Hanus \\ Faculté des Sciences de Luminy, Groupe de Physique des Etats Condensés (*), \\ Case 901, 13288 Marseille Cedex 9, France
}

(Reçu le 12 juillet 1982, accepté le 21 septembre 1982)

\begin{abstract}
Résumé. - Les spectres d'émission lumineuse de cibles de cuivre et d'aluminium ont été mesurés simultanément. Le rapport de ces deux spectres est comparé au calcul théorique de rayonnement de transition. L'épaulement observé a $2,1 \mathrm{eV}$ fournit la première mise en évidence des contributions interbandes du spectre de rayonnement de transition du cuivre.
\end{abstract}

\begin{abstract}
Emission spectra from aluminium and copper targets excited by fast electrons have been measured. The ratio of these two measurements can be directly compared with theoretical transition radiation calculations. A well pronounced shoulder is observed at $2.1 \mathrm{eV}$ giving the first experimental evidence of interband contribution to transition radiation.
\end{abstract}

Light emission from metal targets excited by fast electrons is produced via several physical processes e.g. transition radiation, Bremsstrahlung, and radiative decay of surface plasmons induced by incident electrons.

Transition radiation is emitted when charged particles pass through a dielectric discontinuity with constant velocity. The light is fully polarized in the incident electron plane. The spectrum is continuous with a significant dip near the volume plasma frequency $\left(\omega_{p}\right)$ of the metal, and there is a low energy background varying roughly as the inverse square of the wavelength. This radiation has been theoretically investigated by several authors [1] using Maxwell's equations, assuming the metal can be described by a local dielectric constant.

Bremsstrahlung is produced by electron scattering in the metal. Its intensity is stronger the higher the atomic number of the target, and has an energy dependence $\sim E^{-1}$ [2]. The spectrum and polarization depend on the microscopic model used to describe the interaction between the incident electron and the target.

Radiative decay of electron excited surface plasmons is only allowed if the surface is rough, the radiation being nearly unpolarized [3].

In tnis letter, we give experimental evidence of an interband contribution to the transition radiation spectrum of copper. Two experimental difficulties are generally encountered :

1) The radiation detected in the incident electron plane is not fully polarized and the identification of the component polarized perpendicular to this plane (s polarization) $I_{\mathrm{s}}$ is necessary for interpretation of the measured intensity.

(*) ERA C.N.R.S. 070373. 
Boersch and Sauerbrey [4] have shown that it is possible to separate the transition radiation and Bremsstrahlung contributions to the light emitted by electron excited bulk silver targets using the different dependences of these two components on the electron energy $E$. Light observed was separated into one component proportional to $E$ (identified as transition radiation) and another component proportional to $E^{-1}$ (identified as Bremsstrahlung). With the assumption that the emission components which are not transition radiation are unpolarized, several authors [5] have compared the measured intensity difference $\left(I_{s}-I_{p}\right)$ with transition radiation calculations. In this work, we report that light emitted by aluminium and copper targets excited by fast electrons, is quite fully p-polarized $(P \simeq 80 \%)$. This means that the p-component of this emission can be directly compared to theoretical transition radiation calculations.

2) To study a wide energy spectrum, it is necessary to have knowledge of the efficiency of the detection system. For example, figure 2 shows that the measured copper experimental spectrum is very different from a calculated transition radiation spectrum. In particular, in the experimental spectrum, the small interband contribution structure near $2.1 \mathrm{eV}$ is smoothed out. In the following, we show that by measuring instantaneously the light intensity emitted by alternatively excited copper and aluminium targets, we were able to eliminate the detection system efficiency. This is achieved by comparing experimental and theoretical intensity ratios. All the drifts of the experimental parameters occurring during the time of spectrum measurements are also eliminated. Aluminium has been chosen as reference metal because in this energy range its transition radiation spectrum is smooth and Bremsstrahlung intensity is very weak for this low atomic number metal.

A $5000 \AA$ thick copper film was first evaporated in an ultra vacuum chamber on an optical polished quartz window. The effective part of the film was an $8 \mathrm{~mm}$ diameter disc half the lower part of which was then covered by an aluminium film about $1000 \AA$ thick. These two materials can be considered as semi-infinite media for a study of transition radiation. The chemical cleanness was controlled by Auger spectroscopy. Electrons have a bent trajectory to prevent sample pollution by filament. The energy was $45 \mathrm{keV}$. The electron spot was scanned from the copper to the aluminium target at $100 \mathrm{~Hz}$ frequency.

Electronic gates allowed photon counting only while spot position was either high (copper) or low (aluminium). The validity of our method was controlled on an homogeneous sample (copper or aluminium) and the counting rate obtained was then the same when the spot was either high or low. The mean electron beam current was $I=1 \mu \mathrm{A}$. The radiation intensity was measured with a cooled photomultiplier through a grating monochromator, with a dark count of about $5 \mathrm{cp} / \mathrm{s}$.

On the experimental set up shown in figure 1, one can see that the angle of electron incidence and of observation direction are simultaneously changed by a sample rotation.

Figure 3 shows the experimental ratio $I_{\mathrm{p}} \mathrm{Cu} / I_{\mathrm{p}} \mathrm{Al}$ as a function of spectral energy for three difference observation angles $\left(\theta=32.5^{\circ} ; 47.5^{\circ} ; 57.5^{\circ}\right)$ along with the corresponding theoretical curves.

Theoretical curves have been calculated using Franck's formula [7] which gives the power radiated per frequency interval $d \omega$, within the solid angle $d \Omega$ in the direction $\theta$ of the incident plane for an angle $\alpha$ of the electrons beam :

$$
\frac{\mathrm{d}^{2} I}{\mathrm{~d} \Omega \mathrm{d} \omega}=\frac{e^{2}}{\pi^{2} c} \cos ^{2} \alpha \sin ^{2} \theta \cos ^{2} \theta|\varepsilon-1|^{2} \beta^{2}\left|\varepsilon \cos \theta+\left(\varepsilon-\sin ^{2} \theta\right)^{1 / 2}\right|^{-2}
$$

where $\varepsilon$ is dielectric constant of the metal. We have used values of the dielectric constant compiled by Hagemann et al. [9].

The angle $57.5^{\circ}$ corresponds approximately in our configuration to the direction of maximum emission of copper and aluminium. The corresponding theoretical curve shows a well pronounced 


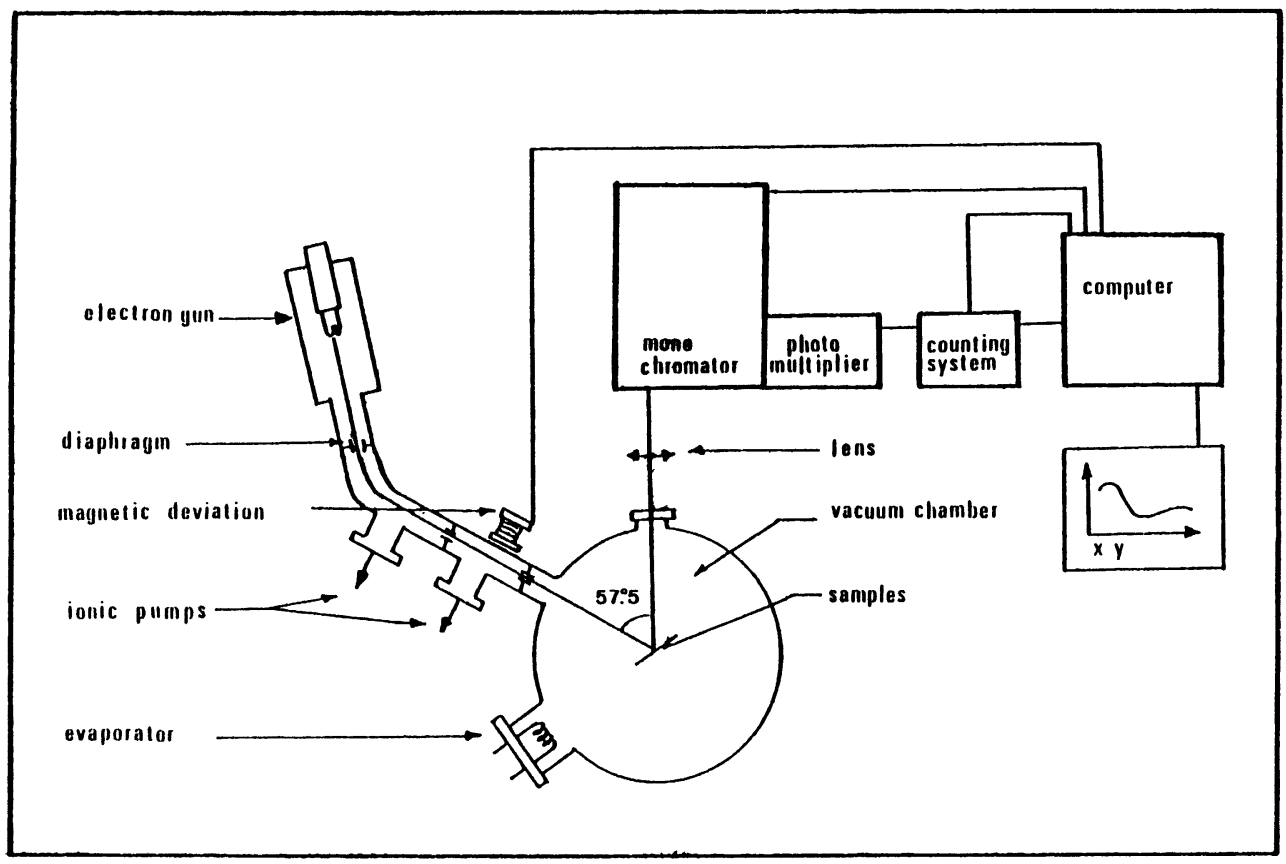

Fig. 1. - Experimental set up.

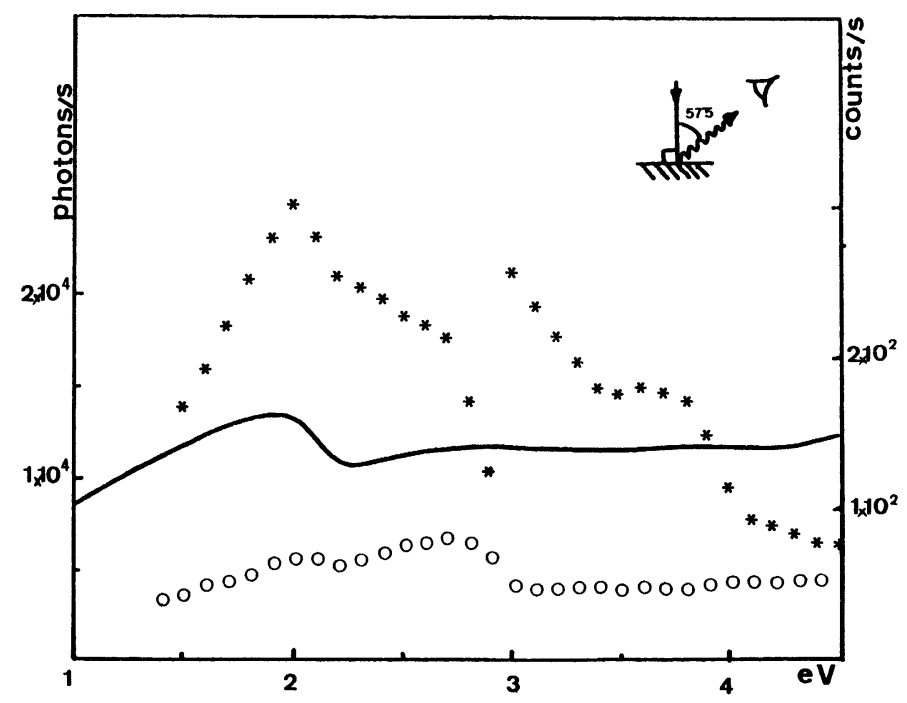

Fig. 2. Calculated intensity of copper transition radiation in our experimental configuration $\mathrm{d} \lambda=50 \AA$, $\mathrm{d} \omega=4 \times 10^{-3}$ sterad., $\alpha=0, \theta=57.5^{\circ}, I=1 \mu \mathrm{A}$ and $V=45 \mathrm{keV}$.

*** Experimental count for $\mathrm{p}$ polarization component on copper film. The decrease of signal is due to the detection system efficiency; grating change and filter interposition explain the modification at $3 \mathrm{eV}$.

OOO Experimental count for s polarization component on copper film. 


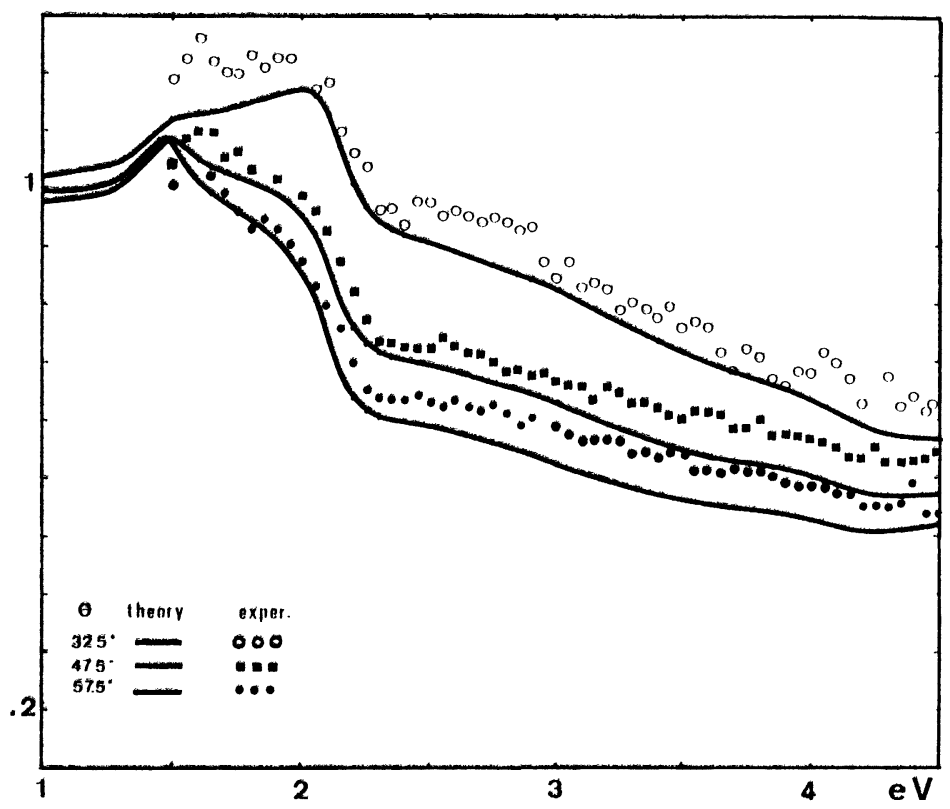

Fig. 3. - Theoretical and experimental ratio $I_{\mathrm{p}} \mathrm{Cu} / I_{\mathrm{p}} \mathrm{Al}$ for three observation angles.

shoulder around $2.1 \mathrm{eV}$ due to electron transitions from higher $\mathrm{d}$ bands $\mathrm{L}_{3}^{\mathrm{u}}$ to the Fermi level of copper [6]. This shoulder is also observed on the experimental curve, with very good agreement between theory and experiment. The theoretical shoulder at $1.5 \mathrm{eV}$ is due to an interband transition of aluminium [7] but the photomultiplier spectral response at this energy is too weak to allow experimental observation. Theoretical and experimental agreement between theory and experiment is very satisfying in the entire spectral range studied ( $1.5 \mathrm{eV}$ to $4.5 \mathrm{eV}$ ). The observation angle $\theta=32.5^{\circ}$ is near the emission lobe edge for the two metals. The intensity emitted is therefore weak and the ratio $I_{\mathrm{p}} \mathrm{Cu} / I_{\mathrm{p}} \mathrm{Al}$ is amplified by the small angular shift between the two lobes. This angular shift can explain the movement of the maximum in the ratio from 1.5 to $2.1 \mathrm{eV}$.

The curve corresponding to the observation angle $\theta=47.5^{\circ}$ shows an intermediate situation. For angles less than $\theta=32.5^{\circ}$, signal becomes too weak to be studied. We have tested the reproducibility of the spectra for different samples of the same metal and for different points of the same sample, and have observed relative variations of intensity of about $10 \%$. The reasons for these variations are not well understood.

Without a better understanding of the origin of these variations, we cannot hope for an agreement between experimental and theoretical results any better than those presented in figure 3 . In spite of this limitation, the detection of very substantially p-polarized observed light, and the good agreement with the transition radiation theory allow us to identify this light as completely dominated by transition radiation, and the structure near $2.1 \mathrm{eV}$ as the interband contribution to the copper transition radiation spectra. Before this work, the comparison between experimental and theoretical results on light emission from electron excited metal surfaces had never given so much information. However the encountered dispersion of results do not allow us to study lesser effects. 


\section{References}

[1] Frank, I. M., Sov. Phys.-Usp, 4 (5) (1962) 740.

Pafomov, V. E., Proc. P. N. Lebedev Phys. Institute, edited by Skobel'Tsyn (Consultants Bureau, New York) 1971, 44, p. 25.

Ginsburg, V. L., Tsytovich, V. N., Phys. Rep. 49 (1979) 1.

[2] JACKsON, Classical electrodynamics (John Wiley and Sons, New York, London) Chap. 15.

[3] Teng, Y. Y., Stern, E. A., Phys. Rev. 19 (1967) 511.

Heitmann, D., Permien, V., Opt. Commun. 25 (1978) 196.

Braundmeier, Jr., Tomasche, H. E., Opt. Commun. 14 (1975) 99.

Heitmann, D., J. Phys. C: Solid State Phys. 10 (1977) 397.

[4] Boersch, H., SAuerbrey, G., Optical properties of metals and alloys, edited by F. Abeles (North Holland, Amsterdam) 1966, p. 386.

Arutyunyan, F. R., Mkhitaryan, A. Kh., Ogonesyan, R. A. and Rostomyan, B. O., Zh. Eksp. Teor. Fiz. 65 (nov. 1973) 1772-1781.

[5] Hattendorf, H. D., Phys. Status Solidi (a) 42 (1977) 489.

[6] Pells, G. P., Shiga, M., J. Phys. C : Solid Stute Phys. Ser. 2,2 (1969).

[7] Gerhardt, U., Phys. Rev. 172 (1968) 651.

[8] Frank, I. M., Sov. Phys.-Usp. 8 (1965) 729.

[9] Hagemann, H. J., Gudat, W., Kunz, C., (Desy SR 74), 7, may 1974. 